\title{
Reticuloendothelial function in coeliac disease and ulcerative colitis
}

\author{
K R PALMER, D C BARBER, S B SHERRIFF, AND C D HOLDSWORTH \\ From the Gastroenterology Unit and Department of Medical Physics, Royal Hallamshire Hospital, Sheffield
}

SUMmary Patients with ulcerative colitis and coeliac disease who had been shown by impaired clearance of heat damaged red cells to have diminished splenic phagocytosis, were examined for evidence of more generalised reticuloendothelial malfunction by measuring their circulatory clearance of micro-aggregated albumin. Although in animals micro-aggregated albumin is largely removed by Kupffer cells, we found impaired clearance in otherwise normal subjects who had previously had surgical splenectomy. In patients with hyposplenism because of bowel disease there was no additional impairment of micro-aggregated albumin clearance, indicating that their hyposplenism is an isolated phenomenon and not part of a generalised reticuloendothelial atrophy. Patients with coeliac disease and normal splenic function had increased reticuloendothelial catabolic activity; this was not present in patients with coeliac disease and abnormal splenic function.

Hyposplenism may be associated with both coeliac disease $^{12}$ and ulcerative colitis. ${ }^{3}$ In both conditions it is probably an effect of the disease as treatment may result in improvement of splenic function, ${ }^{34}$ although if hyposplenism is severe it does not return to normal in either condition.

McCarthy $e t a l^{5}$ suggested that the hyposplenism of coeliac disease was part of a generalised reticuloendothelial abnormality. The evidence for this was that hyposplenic coeliacs had more circulating Howell-Jolly bodies and greater prolongation of rhesus damaged autologous red cell clearance than a group of post-splenectomy control subjects. Lymph nodes removed from hyposplenic coeliacs had less lymphoid tissue and more fibrosis than control patients.

Patients whose ulcerative colitis is complicated by hyposplenism are particularly prone to the development of disseminated intravascular coagulation after proctocolectomy. ${ }^{3}$ This is probably because of an increased susceptibility to the endotoxaemia which frequently accompanies bowel mobilisation. ${ }^{6}$ Splenectomised mice have no increased susceptibility to intravenously administered endotoxin $;^{7}$ intravenously administered isotopically-labelled endotoxin becomes localised within the Kupffer

Received for publication 13 August 1982 cells with practically none fixed in the spleen. ${ }^{8}$ Hyposplenism alone is therefore insufficient to account for the increased susceptibility to endotoxaemia seen in the hyposplenic colitic.

It therefore seems possible that in both coeliac disease and ulcerative colitis, hyposplenism is only one facet of a more generalised abnormality in reticuloendothelial function. We set out to test this hypothesis in patients with ulcerative colitis or with coeliac disease, some of whom had previously been shown to be hyposplenic.

The best available test of overall reticuloendothelial function in man is the micro-aggregated albumin clearance test. ${ }^{9}$ Micro-aggregated albumin, usually labelled with ${ }^{125} \mathrm{I}$, is almost exclusively removed by Kupffer cells ${ }^{9}$ and its rate of circulatory clearance if given in adequate amounts therefore reflects largely hepatic reticuloendothelial phagocytic function. After endocytosis into the macrophage, lysozomal enzymes deiodinise the complex ${ }^{10}$ and the subsequent release of free isotope into the circulation, manifest as a late rise in plasma radioactivity, can be used as an index of reticuloendothelial catabolic function. ${ }^{11}$ We have used the micro-aggregated albumin test to investigate both phagocytic and catabolic aspects of reticuloendothelial function in coeliac disease and ulcerative colitis. 
Methods

\section{PATIENTS}

Three groups were studied (Table).

1 Two control groups, one consisting of six healthy volunteers, the other of five individuals who had undergone surgical splenectomy after trauma.

2 Thirteen patients with adult coeliac disease. At the time of study all were in clinical and histological remission on a gluten-free diet and had normal standard liver function tests.

3 Fourteen individuals with ulcerative colitis. Though only nine of these had total colonic involvement, all had at some stage been severely ill as a result of their disease and had required intensive treatment, including systemic corticosteroids. At the time of study, however, all were in clinical remission with normal standard liver function tests. Thirteen were taking oral sulphasalazine.

The study was approved by the Sheffield Area Health Authority (Teaching) Southern District Ethical Committee and each individual gave informed consent.

In all cases the blood film was examined for the features of hyposplenism. ${ }^{12}$ In addition, all the patients with ulcerative colitis and coeliac disease underwent a heat damaged red cell clearance test, ${ }^{313}$ which is a specific and sensitive test of splenic function, and is independent of Kupffer cell integrity. ${ }^{13}$ All patients classified as hyposplenic (Fig. 1) had a clearance half time longer than the upper limit of 17.5 minutes previously found in 10 normal subjects. ${ }^{3}$ Of the control group, all of the splenectomised, but none of the normal subjects had a blood film typical of hyposplenism. ${ }^{3}$ In our experience this implies that had a heat damaged red cell test been performed it would have been markedly abnormal, with a t $\frac{1}{2}$ of over 40 minutes.

All subjects underwent a micro-aggregated albumin clearance test. The labelled microaggregated albumin complex was prepared by a modification of the method of Iio and Wagner,"

Table Patients studied

\begin{tabular}{lll}
\hline Group studied (no.) & $\begin{array}{l}\text { Mean age (yr) } \\
\text { and range }\end{array}$ & $\begin{array}{l}\text { Ratio } \\
M: F\end{array}$ \\
\hline Control & & \\
$\quad$ Normal (6) & $46 \cdot 8(28-70)$ & $2: 1$ \\
$\quad$ Splenectomy (5) & $52 \cdot 8(21-68)$ & $3: 2$ \\
Coeliac disease & $44 \cdot 5(21-72)$ & $1: 2$ \\
$\quad$ Normosplenic (9) & $55 \cdot 7(40-78)$ & $1: 1$ \\
$\quad$ Hyposplenic (4) & & $3: 4$ \\
Ulcerative colitis & $42 \cdot 3(21-63)$ & $3: 4$ \\
$\quad$ Normosplenic (7) & $40 \cdot 3(13-57)$ & \\
Hyposplenic (7) & &
\end{tabular}

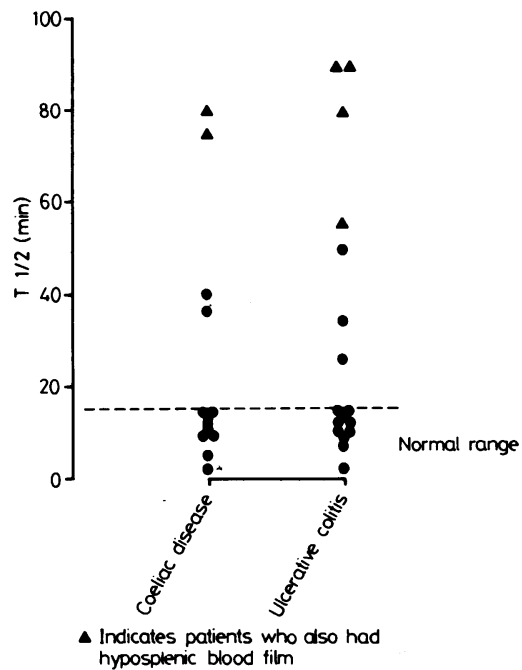

Fig. 1 Splenic function in subjects with coeliac disease and those with ulcerative colitis. $T \frac{1}{2}$ is the clearance half time of heat damaged cells.

using ${ }^{125} I$ rather than ${ }^{131} I$ as the radiation exposure is smaller and the nature of the emission from ${ }^{125} \mathrm{I}$ is less likely to damage the protein during storage ${ }^{14}$ It does, however, have the disadvantage of being less suitable for imaging purposes and surface counting after intravenous administration was therefore not performed. The final concentration of the labelled complex was $30 \mathrm{mg} / \mathrm{ml}$ and the free iodide concentration $12 \%$. Particle size and uniformity were determined by electronmicroscopy of aliquots of micro-aggregated albumin.

In four healthy rabbits blood clearance and organ uptake of micro-aggregated albumin were similar to that reported by others. ${ }^{915}$ Human studies were performed after testing for sterility and pyrogens. Ten $\mathrm{mg} / \mathrm{kg}$ body weight was injected rapidly into a large arm vein and $4 \mathrm{ml}$ samples of blood taken from the other arm into EDTA anticoagulant at frequent intervals up to 180 minutes. After centrifugation the plasma from each sample was divided into a $0.5 \mathrm{ml}$ and $1 \mathrm{ml}$ aliquot. The $0.5 \mathrm{ml}$ sample was placed into an automated counter and the gamma emission counted over 10 minutes. The $1 \mathrm{ml}$ sample was passed through an amberlite- $400(\mathrm{CI})$ resin column in order to remove free iodide. The column was washed through with $10 \mathrm{ml}$ of saline and the eluate also counted for 10 minutes, the $\log _{10}$ values of radioactivity obtained for iodide free plasma were plotted against time, and the time taken for the plasma radioactivity to fall from maximum to $50 \%$ of peak value $\left(t \frac{1}{2}\right)$ determined. The ratio total 
plasma radioactivity:iodide free radioactivity of each sample was then calculated. The value of this ratio at 180 minutes was used as an index of the degree of catabolism of the complex by the reticuloendothelial system as described by Cohen and Carbone. ${ }^{11}$

\section{Results}

Figure 1 presents the results of the splenic function tests in the patients with coeliac disease and in those with ulcerative colitis. Two of the hyposplenic individuals with coeliac disease had circulating Howell-Jolly bodies and four hyposplenic colitics had a similar blood film. As we have found in the past, circulating Howell-Jolly bodies were an indication of more severe hyposplenism, being associated with a heat damaged red cell clearance in the asplenic range (greater than $\mathbf{4 0}$ minutes).

Electron microscopy showed that the particles were uniform in shape and size and had a mean diameter of $27 \pm 0.4 \mathrm{~nm}$ (mean $\pm S D ; n=27$ ). Figure 2 is an example of the circulatory clearance of micro-aggregated albumin in a control subject and shows exponential decay of blood radioactivity after an initial equilibration phase.

Figure 3 shows the $t \frac{1}{2}$ for micro-aggregated albumin clearance in the subjects studied. The $t \frac{1}{2}$ of the splenectomy group was significantly greater than that found in normosplenic subjects (control and bowel disease patients), $\mathrm{p}<0.01$ (Wilcoxon's rank test). The micro-aggregated albumin $t_{\frac{1}{2}}$ of hyposplenic ulcerative colitis and coeliac disease patients was in the same range as that found in the splenectomised subjects, but in none was it greater

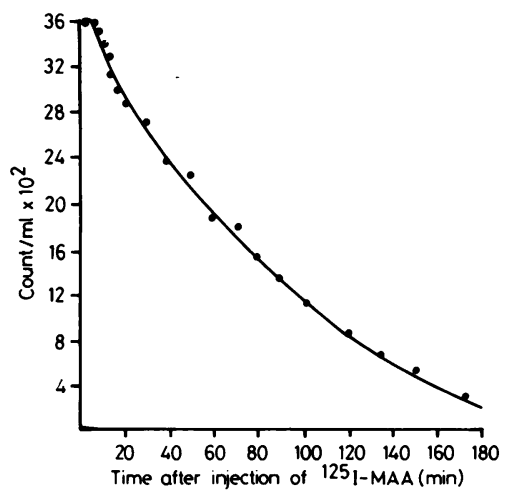

Fig. 2 Circulatory clearance of ${ }^{125}$ I-micro-aggregated albumin in control subject.

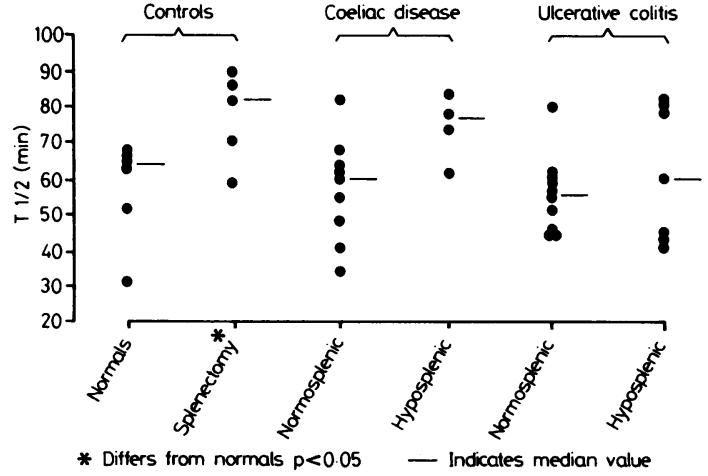

Fig. 3 Results of ${ }^{125}$ I-micro-aggregated albumin circulatory clearance $t_{2}^{\frac{1}{2}}$ in all subjects.

than that found in the splenectomy group.

The ratio total plasma radioactivity:iodide-free radioactivity at 180 minutes (Fig. 4) was significantly greater in the normosplenic coeliac disease patients than in any other group $(p<0 \cdot 05)$.

\section{Discussion}

We have shown that surgical splenectomy is associated with defective micro-aggregated albumin clearance. This was surprising as animal experiments had shown negligible uptake of this material within the spleen. ${ }^{15}$ It may be that the human spleen, unlike that of any other animal, does indeed phagocytose this material. Perhaps more plausible is the alternative that the spleen produces a factor which either by acting as an opsonin or by

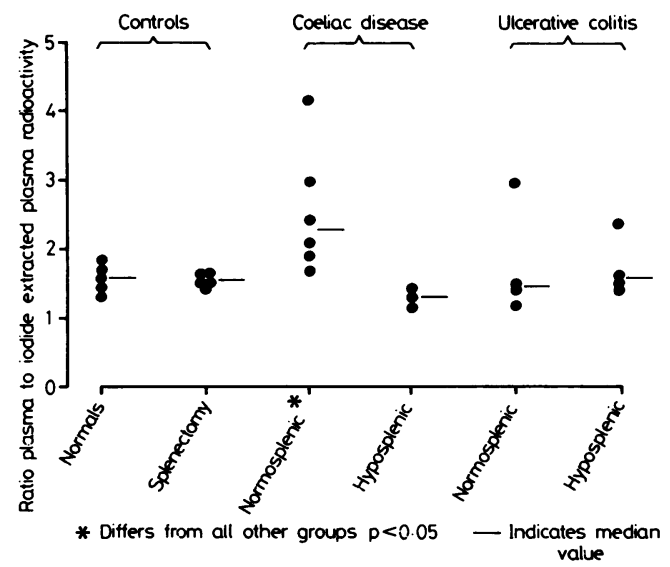

Fig. 4 Reticuloendothelial catabolic function represented by the ratio after 180 minutes of total plasma counts per $\mathrm{ml}$ to counts after removal of free iodide. 
stimulating the remainder of the reticuloendothelial system facilitates phagocytosis. It is probable that the spleen does in fact release opsonins, ${ }^{16}$ although the evidence is conflicting. ${ }^{17}$ It does produce tuftsin, an octapeptide which stimulates phagocytosis in both polymorph leucocyte and macrophages ${ }^{18}$ and serum tuftsin levels determined by radioimmunoassay are low in patients after elective splenectomy. ${ }^{19}$ That such factors are necessary for normal Kupffer cell function has been shown by the in vitro improvement of Kupffer cell function after the addition of an opsonic alpha-2 surface binding protein in hypo-opsonaemic patients. ${ }^{20}$ Furthermore, it has been shown that after splenectomy, the macrophages in the liver require increased amounts of antibody to mediate intravascular clearance of opsonised particles. ${ }^{21}$

If the hyposplenic patients with coeliac disease or ulcerative colitis had generalised reticuloendothelial hypofunction, it would be expected that their clearance $t \frac{1}{2}$ of micro-aggregated albumin would be slower than that of control splenectomised subjects. This was not the case and there is certainly therefore no evidence for any generalised reticuloendothelial phagocytic defect in the hyposplenism accompanying these conditions.

Although three of the four hyposplenic coeliac patients had a $t_{2}^{\frac{1}{2}}$ clearance of micro-aggregated albumin slower than that of the six normal subjects, it was not slower than that of the splenectomised controls, so that whatever generalised reticuloendothelial dysfunction these patients do have is likely to be secondary solely to the loss of splenic tissue. Failure to find abnormal micro-aggregated albumin clearance in our intestinal hyposplenic group is certainly not due to their having only a minor degree of hyposplenism, as even in the four colitics with both Howell-Jolly bodies and severely impaired clearance of heat damaged red cells, mean microaggregated albumin clearance was normal at 65 minutes.

The patients with coeliac disease and normal splenic function had an increased catabolic activity for micro-aggregated albumin as shown by the increased release of ${ }^{125} \mathrm{I}$ (Fig. 4). This enhanced catabolic function is lost in the hyposplenic group, and this is the only evidence we have which would support the suggestion that some aspects of reticuloendothelial function apart from splenic function may be depressed in the hyposplenism of gastrointestinal disease.

Although this study does not yield the answer to the cause of hyposplenism in coeliac disease or ulcerative colitis, it does at least make some possibilities less likely. It is improbable that McCarthy's suggestion ${ }^{5}$ that substances absorbed through the abnormal mucosa lead to hyposplenism, as it is difficult to accept that such materials would preferentially affect the splenic reticuloendothelial cells leaving the hepatic elements untouched. Furthermore, the spleen plays only a minor role in the clearance of these substances. ${ }^{15}$ Bullen's suggestion $^{22}$ that hyposplenism is because of loss of monocytes through a diseased mucosa, attractive in that it might apply to both coeliac disease and ulcerative colitis, becomes unlikely as both splenic and hepatic reticuloendotheliocytes are derived from wandering marrow cells ${ }^{23}$ (though admittedly there is a greater capacity for local Kupffer cell replication). A relationship between immune complex formation and splenic function has been shown in rheumatoid arthritis, ${ }^{24}$ and immune complexes have been demonstrated in coeliac disease $^{25}$ and it may be that the use of receptor specific particles such as $\mathrm{C}_{3} \mathrm{G}$ or IgM coated red cells $^{26}{ }^{27}$ may reveal abnormalities of the reticuloendothelial system undetected by the non-specific micro-aggregated albumin clearance test.

\section{References}

1 Engel A. Om sprue och mjalatrofi. Nord Med 1939; 1: 388-92.

2 Marsh GW, Stewart JS. Splenic function in adult coeliac disease. Br J Haematol 1970; 19: 445-58.

3 Ryan FP, Smart RC, Holdsworth CD, Preston FE. Hyposplenism in inflammatory bowel disease. Gut 1978; 19: 50-5.

4 Palmer KR, Sherriff SB, Holdsworth CD. The changing pattern of splenic function in adult coeliac disease. (Abstract.) Gut 1979; 20: A920.

5 McCarthy CF, Fraser ID, Evans KT, Read AE. Lymphoreticular dysfunction in idiopathic steatorrhoea. Gut 1966; 7: 140-7.

6 Palmer KR, Duerden BI, Holdsworth CD. Bacteriological and endotoxin studies in cases of ulcerative colitis submitted to surgery. Gut 1980; 21: 851-4.

7 Agarwal MK, Parant M, Parant F. Role of spleen in endotoxin poisoning and reticuloendothelial function. Br J Exp Pathol 1972; 53: 485-91.

8 Carey FJ, Braude AJ, Zalesky M. Studies with radioactive endotoxin. III. The effect of tolerance on the distribution of radioactivity after intravenous injection of Escherichia coli endotoxin labelled with ${ }^{51}$ Cr. J Clin Invest 1958; 37: .441-57.

9 Iio M, Wagner HN. Studies of the reticuloendothelial system (R.E.S.). I: Measurement of the phagocytic capacity of the R.E.S. in man and the dog. J Clin Invest 1963; 42: 417-26.

10 Mego JL, Bertini F, McQueen D. The use of form- 
aldehyde treated $\mathrm{I}^{131}$ albumin in the study of digestive vacuoles and some properties of these particles from mouse liver. J Cell Biol 1967; 32: 699-707.

11 Cohen NH, Carbone PP. Measurement of reticuloendothelial system phagocytosis and catabolism, a new method. J Reticuloendothel Soc 1969; 6: 333-43.

12 Crosby WH. Hyposplenism: an inquiry into the normal function of the spleen. Ann Rev Med 1963; 14: 349-70.

13 Marsh GW, Lewis SM, Szurrh L. The use of ${ }^{51} \mathrm{Cr}$ labelled heat-damaged red cells to study splenic function. I. Evaluation of method. Br J Haematol 1966; 12: 161-6.

14 Briner WH. Preparation of ${ }^{125}$ I-labelled microaggregated human serum albumin for use in studies of reticuloendothelial function in man. J Nucl Med 1968; 9: 482-5.

15 Benacerraf B, Biozzi G, Halpern BN, Stiffel C, Mouton D. Phagocytosis of heat-denatured serum albumin labelled with ${ }^{131} I$ and its use as a means of investigating liver blood flow. Br J Exp Pathol 1957; 38: $35-48$.

16 Anderson V, Cohn J, Sørensen SF. Immunological studies in children before and after splenectomy. Acta Paediatr Scand 1976; 65: 409-15.

17 Patterson JT, Pisano JC, Di-Luzio MI. Effect of splenectomy upon restoration of opsonic activity following reticuloendothelial blockade. (Abstract) $J$ Reticuloendothel Soc 1970; 7: 633-4.

18 Najjar VA, Constantopoulos A. A new phagocytosis stimulating tetrapeptide hormone, tuftsin, and its role in disease. J Reticuloendothel Soc 1972; 12: 197-9.
19 Spirer Z, Zakuth V, Diamant S, Mondorf W, Stefanescu T, Stabinsky Y, Fridkin M. Decreased tuftsin concentrations in patients who have undergone splenectomy. Br Med J 1977; 2: 1574-6.

20 Scovill WA, Saba TM, Blumstock FA, Bernard H, Powers SR. Opsonic alpha-2 surface binding glycoprotein therapy during sepsis. Ann Surg 1978; 188: 521-9.

21 Hosea SW, Brown EJ, Hamburger MI, Frank MM. Opsonic requirements for intravascular clearance after splenectomy. N Engl J Med 1981; 304: 245-50.

22 Bullen AW, Losowsky MS. Lymphocyte population in adult coeliac disease. Gut 1978; 19: 892-7.

23 Gale RP, Sparkes RS, Goide DW. Bone marrow origin of hepatic macrophages (Kupffer cells) in humans. Science 1978; 201: 937-8.

24 Williams BD, Russell BA, Lockwood CM, Cotton C. Defective reticuloendothelial system function in rheumatoid arthritis. Lancet 1979; 1: 1311-4.

25 Doe WF, Booth CC, Brown DL. Evidence for complement-binding immune complexes in adult coeliac disease, Crohn's disease and ulcerative colitis. Lancet 1973; 1: 402-3.

26 Jaffe CJ, Vierling JM, Jones AE, Lawley TJ, Frank MM. Receptor specific clearance by the reticuloendothelial system in chronic liver disease. J Clin Invest 1978; 62: 1069-77.

27 Frank MM. Hamburger ML, Lawley TJ, Kimberly RP, Plotz PH. Defective reticuloendothelial system FCreceptor function in systemic lupus erythematosis. $N$ Engl J Med 1979; 300: 518-23. 